DR BERNARD HO (Orcid ID : 0000-0003-2571-3966)

Article type : Correspondence

\title{
Prevalence of vitamin $D$ analogue toxicity in dogs
}

\section{Dear Editor,}

Calcipotriol, calcitriol and tacalcitol are topical vitamin D analogues commonly used to treat psoriasis $^{1}$. As clinicians, although the treatments are often well tolerated, we often consent the known adverse effects ${ }^{1,2}$ such as irritation, erythema, and rarely photosensitivity. Vitamin D analogue toxicity in dogs is rarely reported with only 2 cases reported in veterinary literature ${ }^{3,4}$, and more recently, 2 reports in dermatology literature ${ }^{4,5}$. This is the first published study in reporting the exact number of cases and the clinical effects of vitamin D analogue toxicity in dogs.

410 cases of vitamin D analogue cream ingestions by dogs were reported by the Veterinary Poisons Information Service (VPIS) between 1992 to 2019. Of these 359 cases (87.6\%) were due to calcipotriol ingestion, 32 cases $(7.8 \%)$ involved calcitriol and 19 cases $(4.6 \%)$ were due to tacalcitol ingestion.

Of the 359 canine cases involving calcipotriol cream ingestion, 152 cases had a documented, known outcome. Within these 152 cases, 129 dogs developed signs, 19 dogs died and 17 were euthanised. Of the dogs that developed signs $(n=129)$, there was a fatal outcome in 36 dogs $(27.9 \%)$.

Of the 32 cases involving calcitriol cream ingestion, 9 cases had outcome information documented. All 9 dogs developed signs; 2 dogs were euthanised, 2 died and 5 recovered. Of the dogs that developed signs $(n=9)$, there was a fatal outcome in $4 \operatorname{dogs}(44.4 \%)$.

This article has been accepted for publication and undergone full peer review but has not been through the copyediting, typesetting, pagination and proofreading process, which may lead to differences between this version and the Version of Record. Please cite this article as doi: $\underline{10.1111 / \mathrm{ced} .14499}$

This article is protected by copyright. All rights reserved 
Of the 19 cases involving tacalcitol (Curatoderm) lotion ingestion, 12 cases had clinical outcomes documented, with all 12 dogs developing signs, $6(50 \%)$ dogs died and 1 dog was euthanised.

In order of frequency (Table 1), the reported clinical findings $(n=173)$ from vitamin $D$ analogue ingestion include vomiting $(93,53.8 \%)$, hypercalcaemia $(84,48.6 \%)$, diarrhoea $(35,20.2 \%)$, hyperphosphataemia $(32,18.5 \%)$, renal failure $(26,15 \%)$, polydipsia $(24,13.9 \%)$, and polyuria $(18,10.4 \%)$.

In summary, from the documented outcomes, 59.5\% (103 dogs) recover from their symptoms and the overall mortality rate (including euthanised cases) from vitamin D analogue ingestion was $27.2 \%$ (47 cases). The toxicity studies ${ }^{7}$ in dogs suggest that 1.8 to $3.6 \mu \mathrm{g} / \mathrm{kg} / \mathrm{day}$ of calcipotriol may cause disturbances in calcium homeostasis.

The toxic acute dose of calcipotriol is approximately $10 \mathrm{mcg} / \mathrm{kg}{ }^{8}$ and as little as $67 \mathrm{mcg} / \mathrm{kg}$ can be fatal $^{8}$. A calcipotriol psoriasis cream is typically $50 \mathrm{mcg} / \mathrm{g}$ and a toxic dose of $10 \mathrm{mcg} / \mathrm{kg}$ would be equivalent to only $0.2 \mathrm{~g}$ of cream $/ \mathrm{kg}$.

We believe this is the first study to report the numbers and outcomes of vitamin D analogue toxicity in dogs. The current patient information leaflets on topical vitamin D analogue treatments, including the one found on British Association of Dermatologists and by the manufacturers, do not inform our patients of this risk for their canine companions.

We, as dermatologists and frequent prescribers of topical vitamin D analogues should be aware of this potentially fatal consequence for dogs and it is also our responsibility, and not just the veterinary's, to warn our human patients of the risks to their loved canine companions and advise them how to use and store these medicines safely.

B. Ho, ${ }^{1}$ J. Ellison, ${ }^{2}$ N. Edwards ${ }^{2}$ and N. Bates ${ }^{2}$

${ }^{1}$ Dermatology Department, St. George's Hospital, London, United Kingdom

${ }^{2}$ Veterinary Poisons Information Service, London, United Kingdom

Correspondence: B. Ho 
E-mail: Bernard.ho@nhs.net

https://orcid.org/0000-0003-2571-3966 (B.Ho)

\section{References}

1 Psoriasis - topical treatments Patient Information Leaflet. British Association of Dermatologists. August 2017. London, UK.

2 Dovonex ${ }^{\circledR} 50$ micrograms/g Cream (calcipotriol) Package Leaflet. LEO Laboratories Limited.

Dublin, Ireland.

3 Campbell A. Calcipotriol poisoning in dogs. Vet Rec 1997; 141:27-8 [Letter].

4 Durtnell RE. Canine vitamin D toxicosis. J Small Anim Pract 1999; 40:550 [Letter].

5 Torley D, Drummond A, Bilsland DJ. Calcipotriol toxicity in dogs. Br J Dermatol 2002; 147:1264-1281.

6 Saedi N, Horn R, Muffoletto B, Wood A. Death of a dog caused by calcipotriene toxicity. J Am Acad Dermatol. 2007; 56(4):712-713. doi:10.1016/j.jaad.2006.12.033

7 Fan TM, Simpson KW, Trasti S, Birnbaum N, Center SA, Yeager A. Calcipotriol toxicity in a dog. J Small Anim Pract. 1998;39(12):581-586.

8 Rumbeiha WK Cholecalciferol. In: Peterson ME, Talcott PA (eds). Small Animal Toxicology, 3rd edition. St Louis, Missouri, Elsevier Saunders, 2013, pp489-498.

Funding sources: None

Conflicts of interest: none to declare

Table 1: Frequency of reported adverse clinical effects in dogs after ingestion of vitamin D analogues in cases with known outcome reported to the Veterinary Poisons Information Service (VPIS)

\begin{tabular}{|l|c|c|c|l|}
\hline Agent ingested & Calcipotriol & Calcitriol & Tacalcitol & Total (\%) \\
\hline Total number of dogs & $\mathbf{1 5 2}$ & $\mathbf{9}$ & $\mathbf{1 2}$ & $\mathbf{1 7 3}(\mathbf{1 0 0} \%)$ \\
\hline Clinical signs reported \\
\hline Vomiting & 78 & 7 & 8 & $93(53.8 \%)$ \\
\hline
\end{tabular}




\begin{tabular}{|l|c|c|c|c|}
\hline Hypercalcaemia & 75 & 4 & 5 & $84(48.6 \%)$ \\
\hline Diarrhoea & 31 & 3 & 1 & $35(20.2 \%)$ \\
\hline Hyperphosphataemia & 28 & - & 4 & $32(18.5 \%)$ \\
\hline Renal failure & 21 & 3 & 2 & $26(15.0 \%)$ \\
\hline Polydipsia & 22 & - & 2 & $24(13.9 \%)$ \\
\hline Polyuria & 17 & - & 1 & $18(10.4 \%)$ \\
\hline Collapse & 10 & 3 & 3 & $16(9.2 \%)$ \\
\hline Inappetence/anorexia & 14 & - & - & $14(8.0 \%)$ \\
\hline Azotaemia & 8 & - & 2 & $10(5.8 \%)$ \\
\hline Abdominal discomfort & 8 & - & - & $8(4.6 \%)$ \\
\hline Haematemesis & 5 & 1 & 2 & $8(4.6 \%)$ \\
\hline Tachycardia & 4 & 4 & - & $8(4.6 \%)$ \\
\hline Hypokalaemia & 4 & - & - & $4(2.3 \%)$ \\
\hline Convulsions & 2 & 1 & - & $3(1.7 \%)$ \\
\hline Respiratory distress & 2 & - & 1 & $3(1.7 \%)$ \\
\hline Arrhythmias & 2 & 1 & - & $3(1.7 \%)$ \\
\hline Ataxia & - & - & - & $2(1.2 \%)$ \\
\hline GI haemorrhage & - & - & 1 & $2(1.2 \%)$ \\
\hline Bradypnoea & & 1 & 1 & $1(0.6 \%)$ \\
\hline Cardiorespiratory arrest & 2 & - & - & $1(0.6 \%)$ \\
\hline
\end{tabular}

